
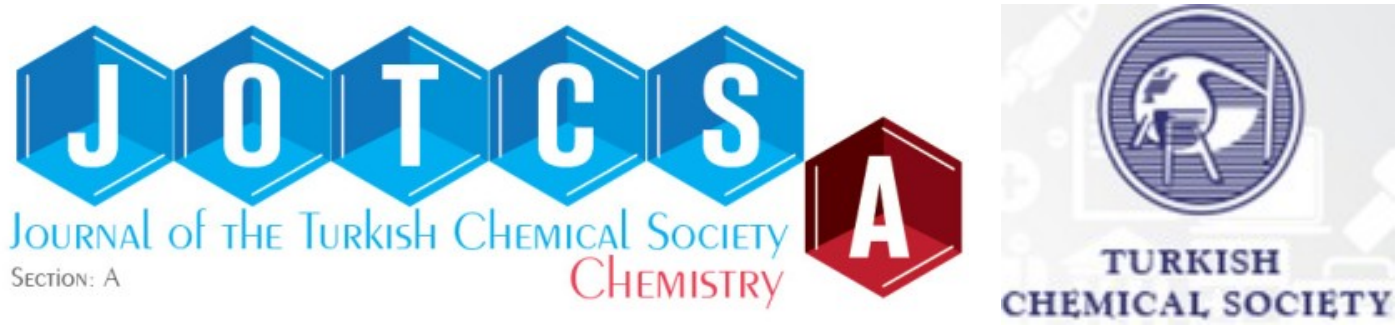

\title{
Synthesis and Characterization of Benzodioxinone-Bearing Methacrylate-Based Random Copolymer via Atom Transfer Radical Polymerization
}

\author{
Cumali Celik $^{1 *}$, Gokhan Acik ${ }^{2}$, GD \\ ${ }^{1}$ Property Protection and Security Department, Yalova Vocational School, Yalova University, Yalova, Turkey \\ ${ }^{2}$ Department of Chemistry, Faculty of Sciences and Letters, Piri Reis University, Tuzla, Istanbul, Turkey
}

\begin{abstract}
Methacrylate-benzodioxinone (BDMA) as a monomer was firstly synthesized and then copolymerized with methyl methacrylate and 2-hydroxyethyl methacrylate via atom transfer radical polymerization (ATRP) in the presence of $\mathrm{CuCl} /$ pentamethyldiethylene triamine (PMDETA) catalytic system using ethyl 2-bromopropionate (EtBrP) as an initiator. Successful formation of the block copolymer was also confirmed in detail by proton nuclear magnetic resonance spectroscopy $\left({ }^{1} \mathrm{H}\right.$ NMR), Fourier-transform infrared spectroscopy (FT-IR), and gel permeation chromatography (GPC) appropriately. Secondly, photochemical acylation of obtained copolymer through hydroxyl and benzodioxinone groups led to the release of benzophenone compound and ester-linkage on the polymer backbone. The formation of ester-linkage increases the glass transition temperature and the thermal stability of the obtained copolymer.
\end{abstract}

Keywords: Atom transfer radical polymerization, ketene chemistry, photochemical acylation, random copolymer.

Submitted: February 12, 2021. Accepted: March 20, 2021.

Cite this: Celik C, Acik G. Synthesis and Characterization of Benzodioxinone-Bearing Methacrylate-Based Random Copolymer via Atom Transfer Radical Polymerization. JOTCSA. 2021;8(2):501-10.

DOI: https://doi.org/10.18596/jotcsa.879021.

*Corresponding author. E-mail: cumali.celik@yalova.edu.tr.

\section{INTRODUCTION}

Copolymers have attracted enormous interest ranging from many industrial fields to another applications in the past two decades (1-4). The development of controlled/living radical polymerizations provides many advantages for producing well-defined polymers $(5,6)$. The reversible addition-fragmentation chain transfer (RAFT), $(7,8)$ atom transfer radical polymerization (ATRP), (9-12) nitroxyl-mediated polymerization (NMP) $(13,14)$ are widely used CLRP methods over the past three decades. Among these methods, ATRP is the most powerful, versatile, and inexpensive method discovered by Matyjaszewski $(5,11,15-18)$. Furthermore, the ATRP can be applied in various monomers under different conditions and provided control over molecular weight, polydispersity, and polymers' topology ( 9 , $10,14)$. This robust method also overcame a wide range of industrial problems, such as tolerance to solvents and impurities $(9-11,19)$.

Recently, benzodioxinone chemistry (20), which can easily form ketene and corresponding ketone intermediates upon UV irradiation (21-24) or temperature exposure thermolysis (25-27), has been utilized in synthetic polymer chemistry (2830). Due to its chemical structure containing carbonyl and alkenyl groups and the possibility of their transformation into ketenes, benzodioxinone compounds are versatile organic reactive intermediates. Also, salicylate esters, one of the most important materials in the medical field (31), can be synthesized by the photochemical acylation process of benzodioxinone in the presence of either phenols or alcohols (32, 33). Recently, this photochemistry has been applied to synthesize various macromolecular architectures by combining various CLRP methods (34). 
This study aims to synthesize photochemically sensitive random copolymer-bearing antagonist benzodioxinone and hydroxyl functionalities via atom transfer radical polymerization with a one-step procedure. For this purpose, methacrylated benzodioxinone was firstly synthesized by esterification reaction of 5-hydroxy-2,2-diphenyl-4Hbenzo[d][1,3]dioxin-4-one with methacryloyl chloride. The methacrylated benzodioxinone monomer was copolymerized with methyl methacrylate and 2-hydroxylethyl methacrylate to get photochemically sensitive random copolymer, by using simple UV irradiation of the resulting copolymer led to photochemical acylation reaction between antagonist benzodioxinone and hydroxyl functionalities. Spectroscopic, chromatographic, and thermal analyses confirmed the formations of obtained copolymer and its acylated species.

\section{MATERIALS AND METHODS}

\section{Materials}

Monomers, methyl methacrylate (Aldrich, MMA, $99 \%$, ), and 2-hydroxyethyl methacrylate (Aldrich, HEMA, 99\%) were purified to remove the inhibitor by passing through a basic alumina column. Copper(I) chloride (Aldrich, $\mathrm{CuCl}, 99.99 \%)$ ethyl 2 bromopropionate (99\%, Aldrich), and methacryloyl chloride (Aldrich, 97\%) were used without further purification. $\quad \mathrm{N}, \mathrm{N}, \mathrm{N}^{\prime}, \mathrm{N}^{\prime \prime}, \mathrm{N}^{\prime \prime}$-pentamethyldiethylene triamine (PMDETA; 99\%, Aldrich) was used as ligand and distilled before use. Toluene (99.7\%, Aldrich) and other solvents were purified prior to use by conventional distillation and drying procedures.

\section{Instrumentation}

The ${ }^{1} \mathrm{H}-\mathrm{NMR}$ analysis was conducted by Agilent NMR System VNMRS 500 spectrometer at room temperature in deuterated chloroform $\left(\mathrm{CDCl}_{3}\right)$ with tetramethylsilane (TMS) as the internal standard. Additionally, Perkin-Elmer FT-IR Spectrum One B spectrometer was used for Fourier transform infrared (FT-IR) spectroscopic analysis. The molecular weights and molecular weight distributions of the resulting polymers were determined by a Viscotek GPCmax. The GPC was equipped with an autosampler system consisting of a pump module (GPCmax, Viscotek, Houston, TX), a refractive index (RI) detector (VE 3580, Viscotek), and a combined light-scattering (Model 270 dual detector, Viscotek). The GPC system was equipped with two columns (LT5000L, Mixed, Medium Organic 300x8 $\mathrm{mm}$ and LT3000L and Mixed, Ultra-Low Organic $300 \times 8 \mathrm{~mm}$ ) with a guard column (TGuard, Organic Guard Column 10x4.6 mm) using tetrahydrofuran eluent at $35{ }^{\circ} \mathrm{C}$ (flow rate, $1 \mathrm{~mL} \mathrm{~min}^{-}$ $\left.{ }^{1}\right)$. The polystyrene standards having narrow molecular weight distribution were used for the calibration of the refractive index detector. Two scattering angles, namely 90 and 7 , were used in the light-scattering detector $\left(\lambda_{0}=670 \mathrm{~nm}\right)$. The GPC data were analyzed using Viscotek OmniSEC Omni-01 software. Perkin-Elmer Diamond TA/ TGA thermogravimetric analysis (TGA) analyzed the thermal stability of obtained polymers with a heating rate of $10{ }^{\circ} \mathrm{C} / \mathrm{min}$ under nitrogen flow (200 mL/min). Also, thermal transitions of obtained polymers were analyzed by Perkin-Elmer Diamond differential scanning calorimetry (DSC) with a heating rate of $10{ }^{\circ} \mathrm{C} / \mathrm{min}$ under nitrogen flow (10 $\mathrm{mL} / \mathrm{min}$ ).

\section{Synthesis of 4-oxo-2,2-diphenyl-4H-benzo[d] [1,3]dioxin-5-yl methacrylate (BDMA)}

Methacrylated benzodioxinone was synthesized with a modified two-step procedure. Firstly, the 5hydroxy-2,2-diphenyl-4H-benzo[d][1,3]dioxin-4-one

(1), was prepared as reported previously (35). In the second step, hydroxyl function of (1) was converted to methacrylate (2) by esterification using methacryloyl chloride according to the procedure given below (Scheme 1);<smiles>O=C1OC(c2ccccc2)(c2ccccc2)Oc2ccccc21</smiles>

(1)<smiles>C=C(C)C(=O)Cl</smiles>

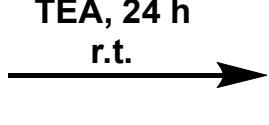<smiles>C=C(C)C(=O)Oc1cccc2c1C(=O)OC(c1ccccc1)(c1ccccc1)O2</smiles>

(2, BDMA)

Scheme 1. Synthesis of 4-oxo-2,2-diphenyl-4H-benzo[d][1,3]dioxin-5-yl methacrylate (BDMA).

A solution of the above-obtained benzodioxinone, (1), $(0.6 \mathrm{~g}, 1.88 \mathrm{mmol})$, and a 1.05 molar equivalent of triethylamine were added into dry acetone, and the solution was cooled to $0{ }^{\circ} \mathrm{C}$. Then, $1.05 \mathrm{~mol}$ of methacryloyl chloride per mol of alcohol was added drop-wise into the solution with vigorous stirring. After that, the suspension was stirred for $24 \mathrm{~h}$ at room temperature. The resulting salt firstly precipitated out, and then it was filtered off. The BDMA monomer was obtained by distillation of the acetone, unreacted methacryloyl chloride, and triethylamine under low pressure. Finally, the BDMA monomer yielded an oily yellow liquid (BDMA, 70\%).

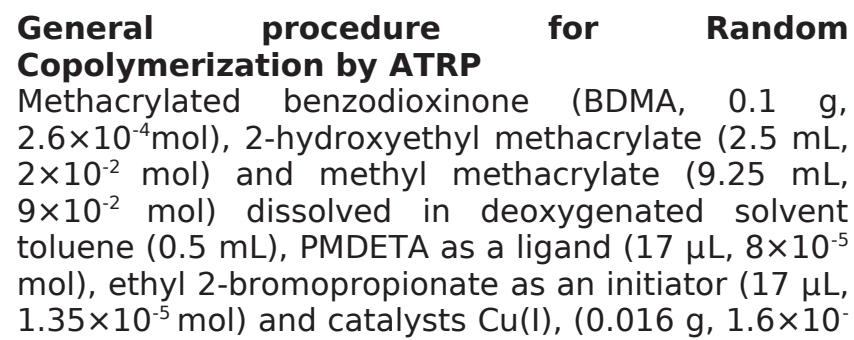


${ }^{4} \mathrm{~mol}$ ) were added to a Schlenk tube equipped with a magnetic stirring bar. The reaction tube was then degassed by three freeze-pump-thaw cycles and was placed in an oil bath $\left(90^{\circ} \mathrm{C}\right)$ for $48 \mathrm{~h}$. The ATRP of BDMA, MMA, and HEMA was stopped by exposing to air. The reaction mixture was diluted with THF and passed through a short basic silica column to remove the copper catalyst. Then the reaction solution was concentrated by rotary evaporation and precipitated in 10-fold excess cold methanol. The obtained copolymer (PBDMA-CO-PHEMA-CO-PMMA) was filtered and dried under a vacuum oven at room temperature (yield: 20\%; determined gravimetrically).

Photochemical acylation process of PBDMA-coPHEMA-co-PMMA

Previously synthesized PBDMA-Co-PHEMA-CO-PMMA in THF (30 $\mathrm{mL}$ ) were added to a quartz tube and irradiated for $48 \mathrm{~h}$ by a merry-go-round type UVreactor equipped with 16 Philips 8 W/06 lamps and a cooling system. All lamps emitted light at $\lambda>350$ $\mathrm{nm}$. After the given time, the acylated copolymer first was precipitated in methanol, then collected by filtration. The filtrated copolymer was then dried under vacuum for $24 \mathrm{~h}$ at room temperature. Upon UV irradiation, benzophenone was released as a by- product removed by precipitation step using methanol as solvent.

\section{RESULTS AND DISCUSSION}

Based on previous literature studies that gave information about benzodioxinone photochemistry for various synthetic approaches, we synthesized copolymer including photosensitive benzodioxinone benefiting from ketene's chemoselective reactions intermediates toward hydroxyl groups in the copolymer backbone. For this purpose, firstly, methacrylated benzodioxinone (BDMA) was synthesized by esterification reaction of phenolic benzodioxinone 5-hydroxy-2,2-diphenyl-4H-benzo[d] $[1,3]$ dioxin-4-one with methacryloyl chloride (Scheme 1). The chemical structure of BDMA was confirmed by ${ }^{1} \mathrm{H}-\mathrm{NMR}$ spectroscopy detecting characteristic protons of benzodioxinone $(c, d, e, f$, $\mathrm{g}, \mathrm{h}, \mathrm{i}, \mathrm{j})$ and methacrylate $(\mathrm{a}$ and $\mathrm{b})$ at 6.5-7.6, 1.6, and $6.1 \mathrm{ppm}$ (Figure 1).

In the second step, the random copolymerization of BDMA, 2-hydroxylethyl methacrylate, and methyl methacrylate was done by ATRP at $90{ }^{\circ} \mathrm{C}$ in toluene using EtBrP and $\mathrm{CuCl} / \mathrm{PMDETA}$ as initiator and catalyst, respectively (Scheme 2 ).

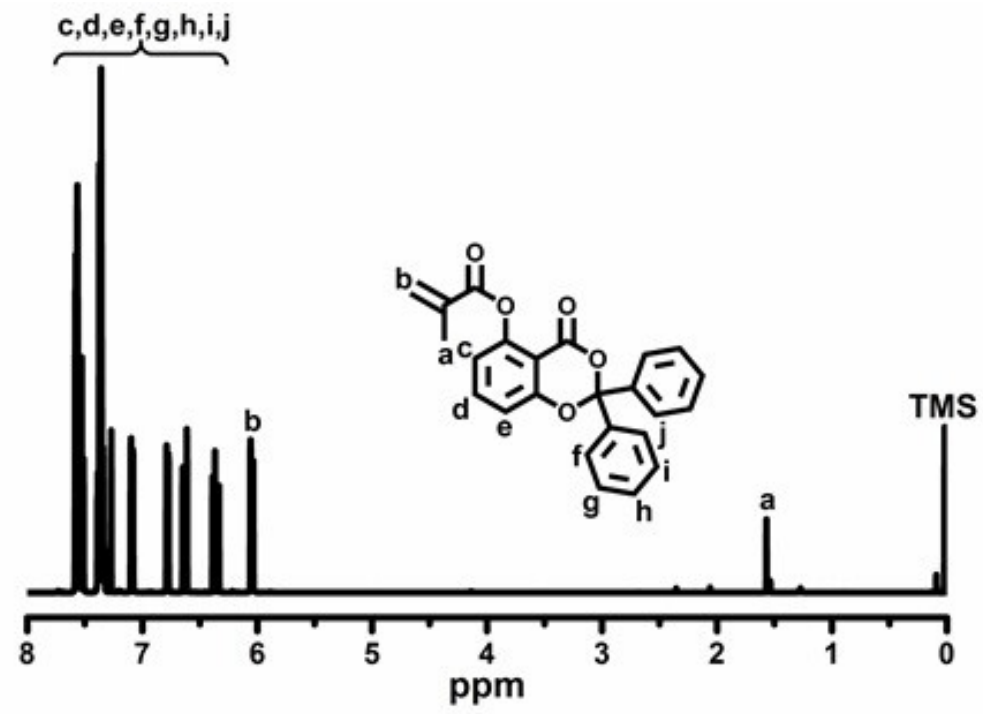

Figure 1. ${ }^{1} \mathrm{H}-\mathrm{NMR}$ spectrum of BDMA.

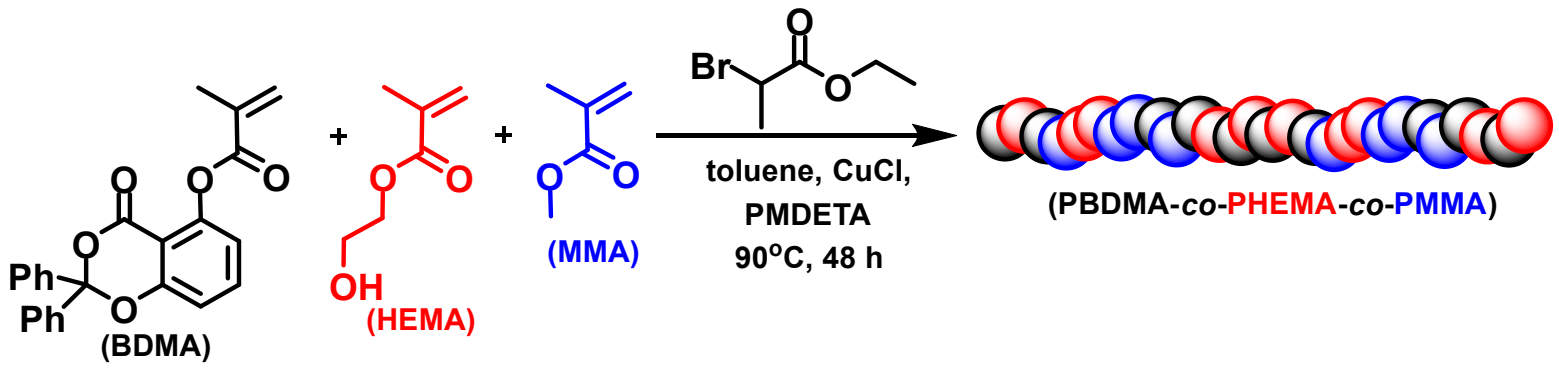

Scheme 2. Copolymerization of BDMA, HEMA and MMA via ATRP. (BDMA:HEMA:MMA:PMDETA:EtBrP:CuCl = 1:80:350:0.3:0.05:0.6 in 0.6 mL xylene) 
The successful ATRP copolymerization led to photochemically active copolymer (PBDMA-coPHEMA-Co-PMMA), including benzodioxinone, which can absorb near UV light. In the final stage, the photochemical acylation process of the obtained PBDMA-Co-PHEMA-Co-PMMA was achieved throughout $48 \mathrm{~h}$ under UV light (Scheme 3).

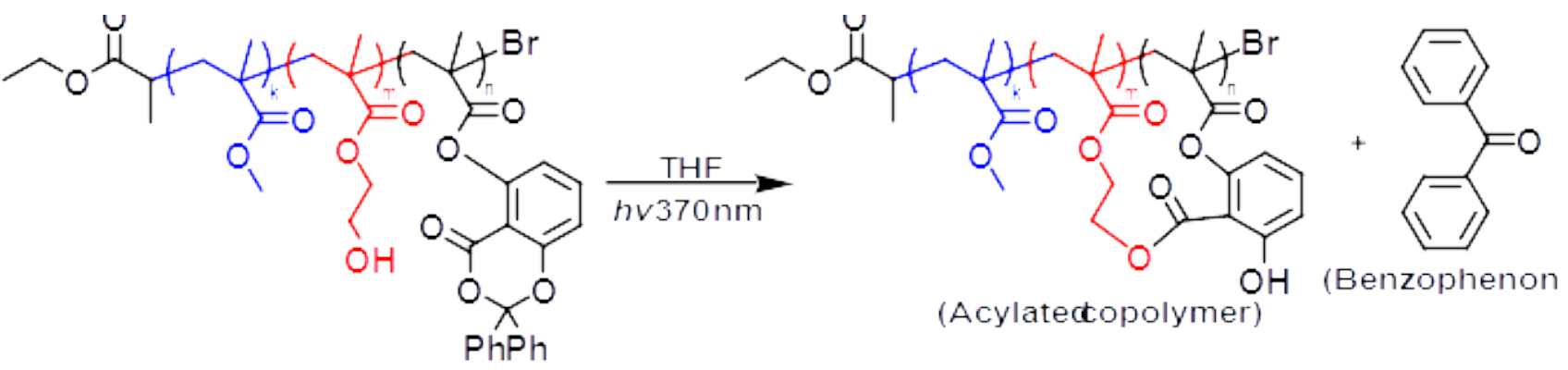

(PBDMAGOPHEMACOPMMA

Scheme 3. Photochemical acylation of PBDMA-Co-PHEMA-co-PMMA.

Based on spectroscopic (FT-IR and ${ }^{1} \mathrm{H}-\mathrm{NMR}$ ) and chromatographic (GPC) data of obtained copolymer by ATRP, the random copolymer was obtained with good yield as evaluated by acceptable monomer conversion $(20 \%)$ and molecular weight $\left(M_{n}=73.730\right.$ $\mathrm{g} / \mathrm{mol}$ ) and molecular weight distribution (PDI= 1.26). The FT-IR spectra of untreated and UV-treated PBDMA-CO-PHEMA-Co-PMMA copolymer were shown in Figure 2. The spectrum for the neat PBDMA-coPHEMA-CO-PMMA displayed the characteristic bands such as broad $\mathrm{O}-\mathrm{H}$ band at $3500 \mathrm{~cm}^{-1}$, aromatic $\mathrm{C}-\mathrm{H}$ band at $2950 \mathrm{~cm}^{-1}$, sharp $\mathrm{C}=\mathrm{O}$ band at $1700 \mathrm{~cm}^{-1}$, aromatic $\mathrm{C}=\mathrm{C}$ band at $1450 \mathrm{~cm}^{-1}$ at and $\mathrm{C}-\mathrm{O}$ band at $1250 \mathrm{~cm}^{-1}$. After the photochemical acylation process, all characteristic bands of PBDMA-COPHEMA-Co-PMMA were presented, whereas a new band at $1625 \mathrm{~cm}^{-1}$ attributed to the intramolecular hydrogen-bonded carbonyl group was formed.
Although FT-IR results confirmed the copolymer formation and acylation, the ${ }^{1} \mathrm{H}-\mathrm{NMR}$ analysis provided a powerful indication. As can be seen, the Figure 3, the presence of aromatic protons belonging to PBDMA appear very clear between 6.10 and $7.50 \mathrm{ppm}(\mathbf{n}, \mathbf{o}, \mathbf{p}, \mathbf{r}, \mathbf{s}, \mathbf{t}, \mathbf{u}$ and $\mathbf{v})$, PHEMA at 3.85 and 4.10 ppm ( $\mathbf{k}$ and $\mathbf{j}$ ), and PMMA at 3.58 ppm (g) prove the successful formation of copolymer bearing UV light-sensitive benzodioxinone. In addition, the chemical composition of the copolymer could be calculated from the integration ratio of methoxy protons of MMA (-O- $\left.\mathrm{CH}_{3}, \mathbf{g}\right)$ at $3.58 \mathrm{ppm}$, methylene protons ($\mathrm{CH}_{2^{-}}, \mathbf{j}$ and $\mathbf{k}$ ) of HEMA at $4.10 \mathrm{ppm}$ and $3.95 \mathrm{ppm}$ and the aromatic protons $(\mathbf{n}, \mathbf{o}, \mathbf{p}, \mathbf{r}, \mathbf{s}, \mathbf{t}, \mathbf{u}$ and $\mathbf{v})$ of benzodioxinone at 6.10 and $7.50 \mathrm{ppm}$. According to the ${ }^{1} \mathrm{H}-\mathrm{NMR}$ calculation, the copolymer composition was found as $8.7,29.0$, and $62.3 \%$ for PBDMA, PHEMA, and PMMA, respectively.

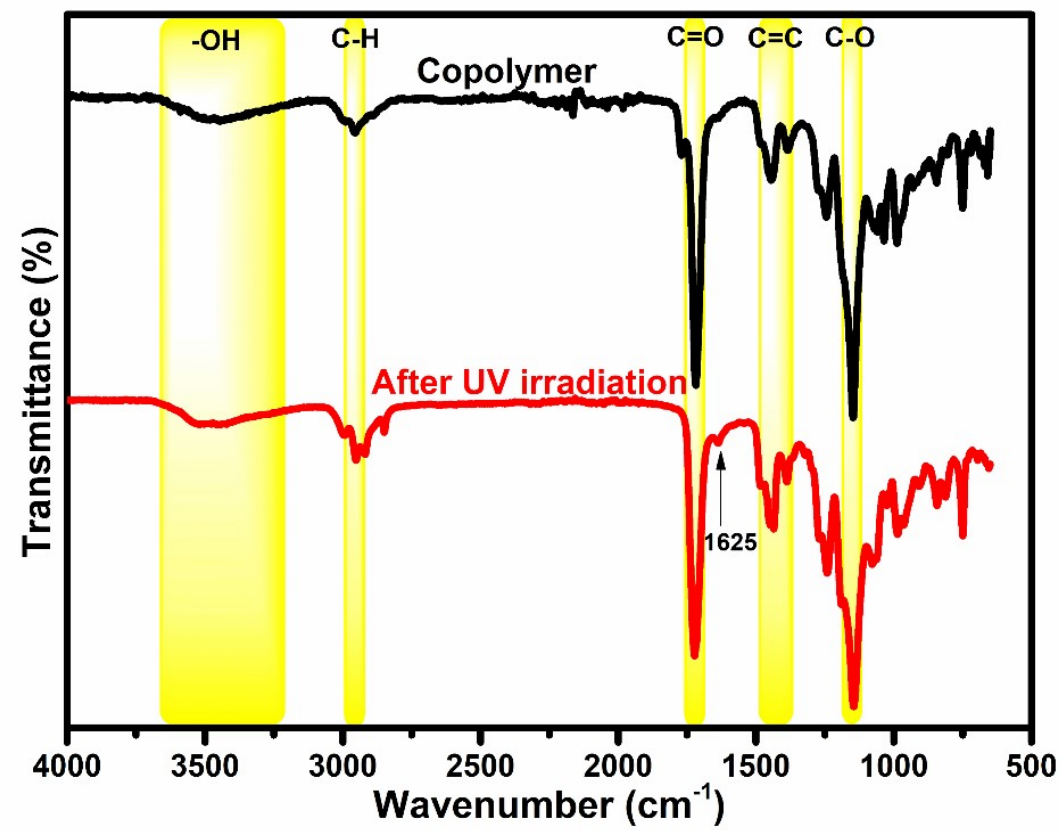

Figure 2. FT-IR spectra of PBDMA-CO-PHEMA-CO-PMMA and it's acylated species after UV irradiation. 
The photoinduced acylation reaction antagonist benzodioxinone and hydroxyl groups of the PBDMACo-PHEMA-CO-PMMA led to the acylated product. After the acylation process, the aromatic peaks at $6.10 \mathrm{ppm}$ and $6.18 \mathrm{ppm}(\mathbf{n}, \mathbf{0}$, and $\mathbf{p})$ coming from benzodioxinone were remarkably decreased, whereas the aromatic peaks at $6.98 \mathrm{ppm}$ and 7.08 $\operatorname{ppm}(\mathbf{r}, \mathbf{s}, \mathbf{t}, \mathbf{u}$ and $\mathbf{v}$ ) belonging benzene rings of leaving benzophenone were almost disappeared.

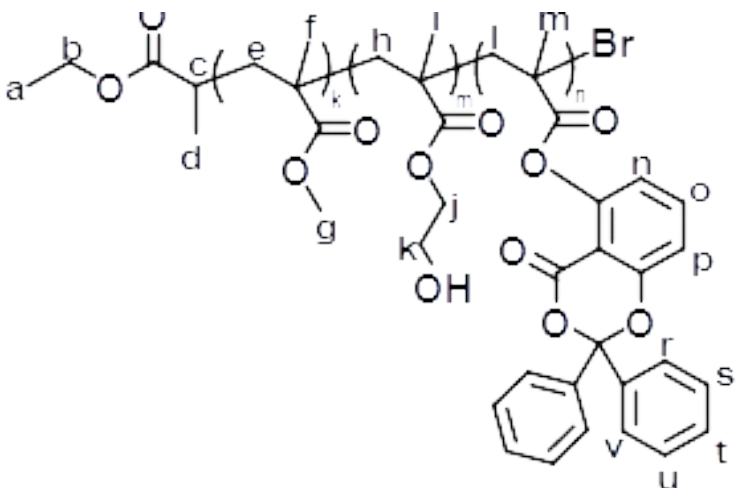

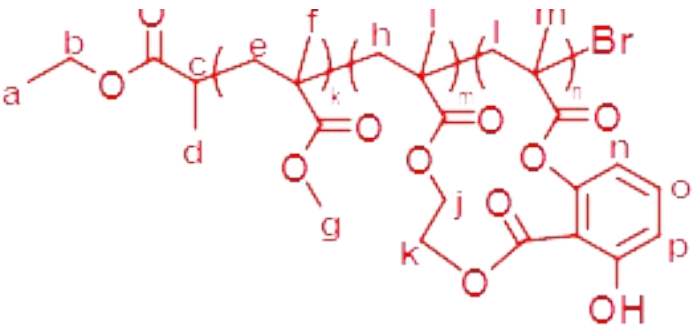

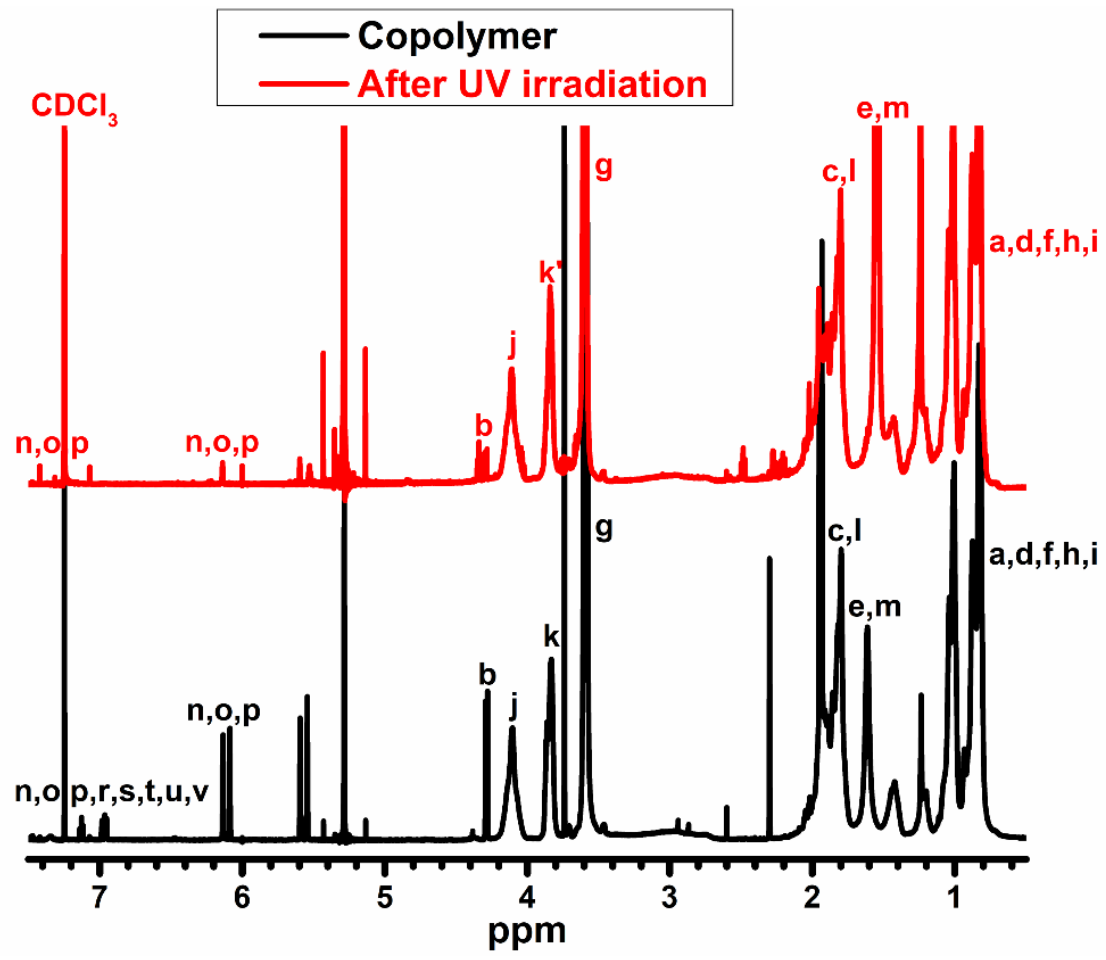

Figure 3. ${ }^{1} \mathrm{H}-\mathrm{NMR}$ spectra of BDMA-CO-PHEMA-CO-PMMA and its acylated species after UV light irradiation. The random copolymer composition was calculated by ${ }^{1} \mathrm{H}-\mathrm{NMR}$ analysis using the following formula:

$($ Composition $=(\mathbf{n}+\mathbf{o}+\mathbf{p}+\mathbf{r}+\mathbf{s}+\mathbf{t}+\mathbf{u}+\mathbf{v}) /(\mathbf{n}+\mathbf{o}+\mathbf{p}+\mathbf{r}+\mathbf{s}+\mathbf{t}+\mathbf{u}+\mathbf{v}+\mathbf{g}+\mathbf{j}+\mathbf{k}) \times 100$

and $(\mathbf{j}+\mathbf{k}) /(\mathbf{n}+\mathbf{o}+\mathbf{p}+\mathbf{r}+\mathbf{s}+\mathbf{t}+\mathbf{u}+\mathbf{v}+\mathbf{g}+\mathbf{j}+\mathbf{k}) \times 100$, where $\mathbf{n}+\mathbf{o}+\mathbf{p}+\mathbf{r}+\mathbf{s}+\mathbf{t}+\mathbf{u}+\mathbf{v}$ represents the integrated peak area at between $6.10 \mathrm{ppm}$ and $7.50 \mathrm{ppm}$ corresponding to aromatic protons of benzodioxinone, j+k represents the integrated peak area at $4.10 \mathrm{ppm}$ and $3.95 \mathrm{ppm}$ methylene protons $\left(-\mathrm{CH}_{2}-\right)$ of $\mathrm{HEMA}$ and $\mathbf{g}$ represents the integrated peak area at $3.58 \mathrm{ppm}$ methoxy protons $\left(-\mathrm{O}-\mathrm{CH}_{3}\right)$ of MMA). 


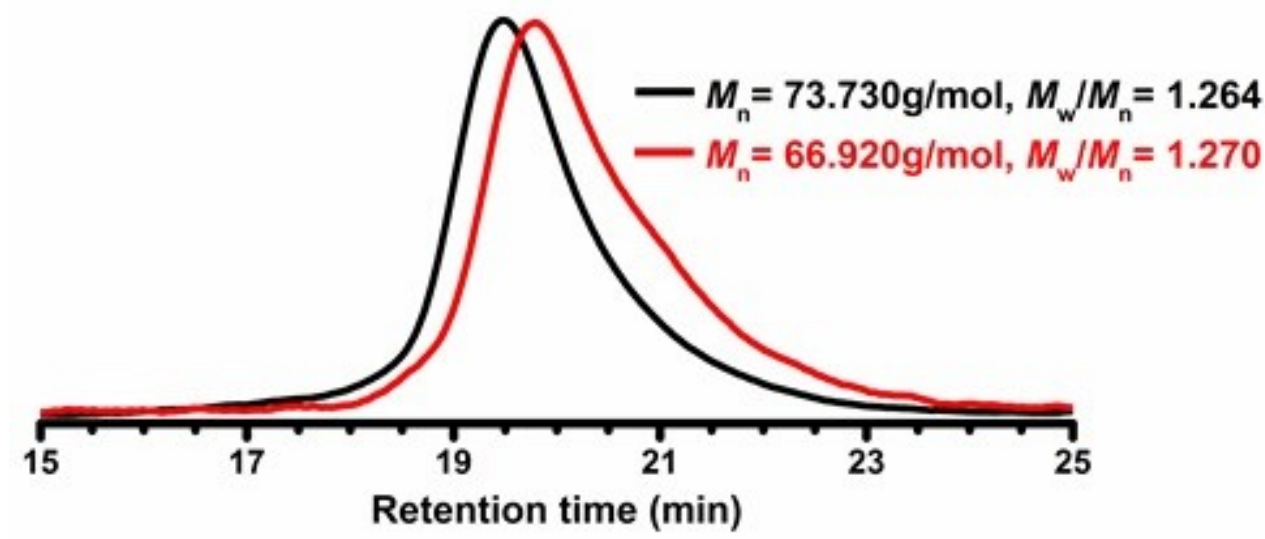

Figure 4. The GPC traces of PBDMA-CO-PHEMA-CO-PMMA and its acylated species after UV light irradiation (All GPC measurements were conducted using tetrahydrofuran as eluent with flow rate, $1 \mathrm{~mL} \mathrm{~min}^{-1}$ at $35^{\circ} \mathrm{C}$ ).

The thermal properties of the PBDMA-co-PHEMA-coPMMA and its acylated species after esterification were determined by differential scanning calorimetric (DSC) analysis under a nitrogen atmosphere, and compared with pristine PHEMA-COPMMA (Figure 5). The PHEMA-CO-PMMA exhibited a glass transition temperature $\left(T_{\mathrm{g}}\right)$ at $88^{\circ} \mathrm{C}$, whereas the obtained PBDMA-Co-PHEMA-Co-PMMA and its acylated species copolymers displayed higher $T_{\mathrm{g}}$ values at 98 and $109{ }^{\circ} \mathrm{C}$, respectively. Due to the rigid benzodioxinone segments, the $T_{g}$ value of PBDMA-CO-PHEMA-Co-PMMA higher than PHEMA-CoPMMA. After the acylation process, the linear polymer chains become entrapped within the particle, leading to decreased free volume. Therefore, the acylated species have the highest $T_{\mathrm{g}}$ value compared to the PBDMA-Co-PHEMA-Co-PMMA and PHEMA-CO-PMMA (36-40).

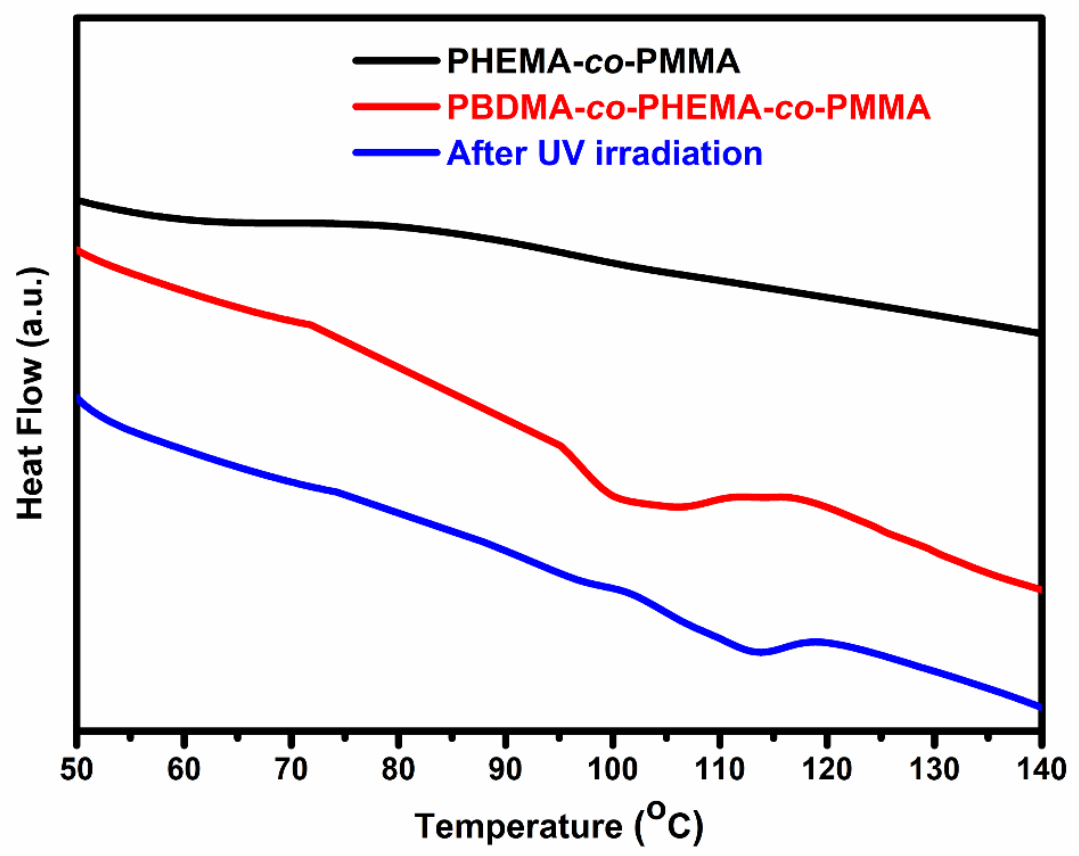

Figure 5. DSC thermogram of PHEMA-Co-PMMA, PBDMA-Co-PHEMA-co-PMMA, and its acylated species after UV light irradiation.

TGA further explored the thermal stabilities of the PHEMA-Co-PMMA, PBDMA-Co-PHEMA-Co-PMMA, and its acylated species under nitrogen atmosphere. As shown in Figure 6 , the weight loss of PHEMA-coPMMA began at about $322{ }^{\circ} \mathrm{C}$, reached its maximum at $440{ }^{\circ} \mathrm{C}$, and displayed a single peak indicating one-step thermal degradation. The inclusion of benzodioxinone compounds on to polymer backbone, the rigid aromatic rings improved the thermal stability of the PBDMA-CO-PHEMA-CO-PMMA. However, the PBDMA-CO-PHEMA-CO-PMMA showed two-step degradations due to benzophenone's release and degradation of the polymer backbone. After the acylation process, the copolymer displayed one-step degradation and enhanced thermal stability again compared to the PBDMA-Co-PHEMAco-PMMA (40-42). 


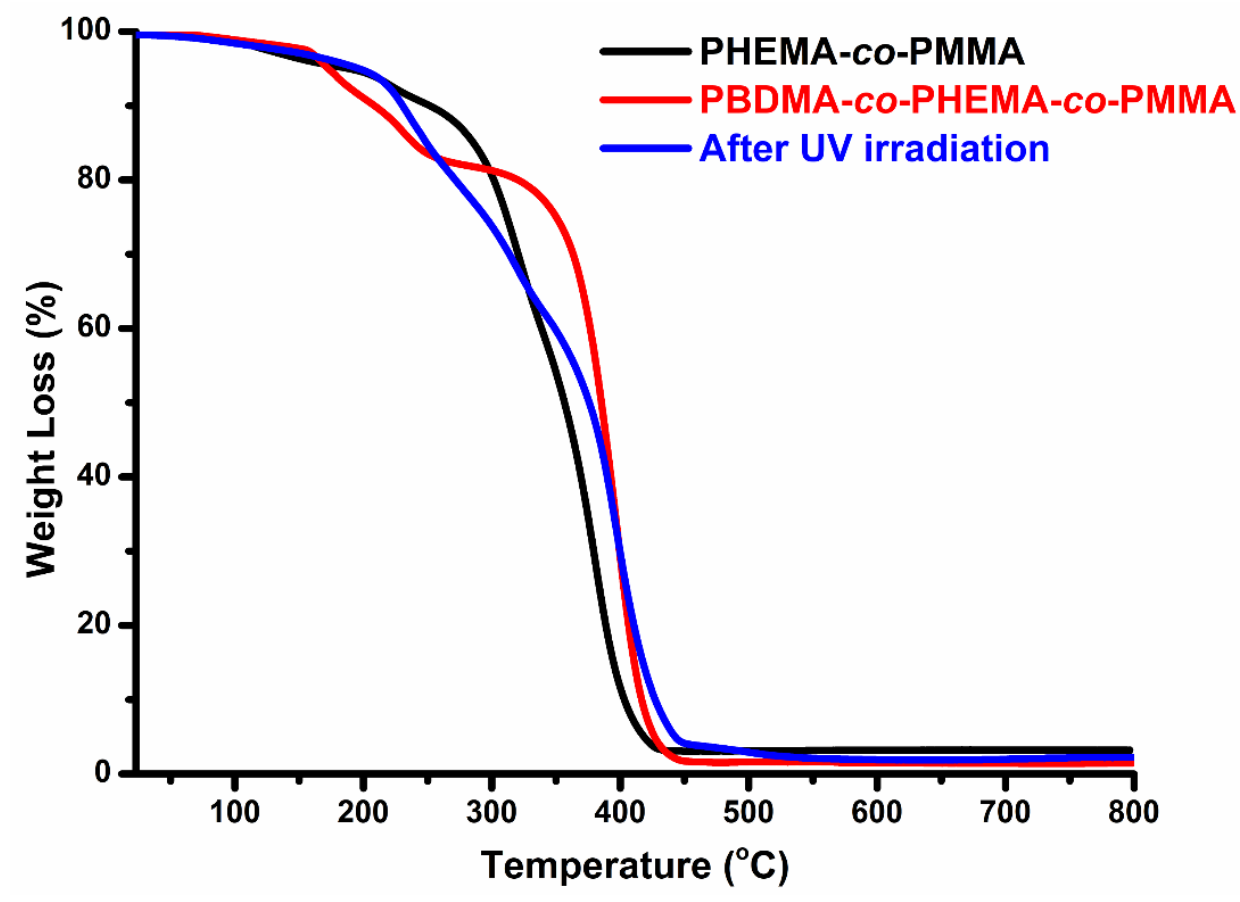

Figure 6. TGA thermogram of PHEMA-Co-PMMA, BDMA-Co-PHEMA-co-PMMA, and its acylated species after UV light irradiation.

\section{CONCLUSION}

In summary, a methacrylated benzodioxinone was synthesized under a mild condition and used as a co-monomer with 2-hydroxyethyl methacrylate and methyl methacrylate in the ATRP process to obtain random copolymer in one-step. The ester formation occurred through benzodioxinone's carbonyl group and the hydroxyl group of HEMA via acylation reaction upon UV photolysis. The formations of the obtained copolymer and its acylated species were confirmed by spectroscopic, chromatographic, and thermal analyses. The characteristic aromatic bands of benzodioxinone in the FT-IR and ${ }^{1} \mathrm{H}-\mathrm{NMR}$ spectroscopies confirmed the chemical attachment of methacrylated benzodioxinone onto the linear polymer chain. In addition to this, the successful detection of ester bands in the FT-IR and ${ }^{1} \mathrm{H}-\mathrm{NMR}$ spectroscopies was also proved the acylation process between antagonist benzodioxinone and hydroxyl groups of the PBDMA-CO-PHEMA-CO-PMMA. A slight decrease of the molecular weight after the photochemical acylation process was remarkably detected by gel permeation chromatography. Furthermore, thermal stabilities of the PBDMA-COPHEMA-Co-PMMA and its acylated product were also compared by DSC and TGA analyses. After the photochemical acylation process, thermal stability and glass transition temperature were clearly increased compared to the pristine PBDMA-COPHEMA-CO-PMMA.

\section{REFERENCES}

1. Klok HA, Lecommandoux S. Supramolecular materials via block copolymer self-assembly. Advanced Materials. 2001; 13(16): 1217-29.

2. Grayson SM, Frechet JM. Convergent dendrons and dendrimers: from synthesis to applications. Chemical Reviews. 2001; 101(12): 3819-68.

3. Cho I. New ring-opening polymerizations for copolymers having controlled microstructures. Progress in Polymer Science. 2000; 25(8): 1043-87.

4. Song A, Parker KA, Sampson NS. Synthesis of copolymers by alternating ROMP (AROMP). Journal of the American Chemical Society. 2009; 131(10): 3444-5.

5. Wang JS, Matyjaszewski K. "Living"/Controlled Radical Polymerization. Transition-Metal-Catalyzed Atom Transfer Radical Polymerization in the Presence of a Conventional Radical Initiator. Macromolecules. 1995; 28(22): 7572-3.

6. Kato $M$, Kamigaito $M$, Sawamoto $M$, Higashimuro T. Polymerization of methyl methacrylate with the carbon tetrachloride/dichlorotris(triphenylphosphine) ruthenium (II)/methylaluminum bis (2, 6-di-tert-butylphenoxide) initiating system: possibility of living radical polymerization. Macromolecules. 1995; 28(5): 1721-3.

7. Rizzardo E, Chiefari J, Mayadunne R, Moad G, Thang S. Tailored polymer architectures by reversible addition-frasmentation chain transfer. Macromolecular Symposia. 2001; 174(1): 209-12. 
8. Barner-Kowollik C, Davis PT, Heuts PAJ, Stenzel HM, Vana $P$, Whittaker $M$. RAFTing down under: Tales of missing radicals, fancy architectures, and mysterious holes. Journal of Polymer Science Part A: Polymer Chemistry. 2003; 41(3): 365-75.

9. Matyjaszewski K, Xia J. Atom transfer radical polymerization. Chemical Reviews. 2001; 101(9): 2921-90.

10. Kamigaito $M$, Ando $T$, Sawamoto $M$. Metalcatalyzed living radical polymerization. Chemical Reviews, 2001; 101(12): 3689-746.

11. Wang JS, Matyjaszewski K. Controlled/"living" radical polymerization. Atom transfer radical polymerization in the presence of transition-metal complexes. Journal of the American Chemical Society. 1995; 117(20): 5614-5.

12. Percec V, Barboiu B. "Living" Radical Polymerization of Styrene Initiated by Arenesulfonyl Chlorides and Cul (bpy) $\mathrm{nCl}$. Macromolecules. 1995; 28(23): 7970-2.

13. Georges MK, Veregin RPN, Kazmaier PM, Hemer GK. Narrow molecular weight resins by a free-radical polymerization process. Macromolecules. 1993; 26(11): 2987-8.

14. Hawker CJ, Bosman AW, Harth E. New polymer synthesis by nitroxide mediated living radical polymerizations. Chemical Reviews. 2001; 101(12): 3661-88.

15. Patten TE, Xia J, Abernathy T, Matyjaszewski K. Polymers with very low polydispersities from atom transfer radical polymerization. Science. 1996; 272(5263): 866-8.

16. Wang JS, Matyjaszewski K. Controlled/"living" radical polymerization. Halogen atom transfer radical polymerization promoted by a $\mathrm{Cu}$ (I)/Cu (II) redox process. Macromolecules. 1995; 28(23): 790110.

17. Matyjaszewski K. New (co) polymers by atom transfer radical polymerization. Macromolecular Symposia. 1999; 143(1): 257-68.

18. Matyjaszewski K. General concepts and history of living radical polymerization. Handbook of Radical Polymerization. 2002; 361-406.

19. Patten TE, Matyjaszewski K. Copper (I)-catalyzed atom transfer radical polymerization. Accounts of Chemical Research. 1999; 32(10): 895-903.

20. Tasdelen MA, Yagci Y. Benzodioxinone Photochemistry in Macromolecular Science: Progress, Challenges, and Opportunities. ACS Macro Letters. 2017; 6(12): 1392-7.
21. Kumbaraci V, Talinli N, Yagci Y. Photoinduced synthesis of oligoesters. Macromolecules. 2006; 39(18): 6031-5.

22. Tasdelen MA, Kumbaraci V, Talinli N, Yagci Y. Photochemically masked benzophenone: Photoinitiated free radical polymerization by using benzodioxinone. Polymer. 2006; 47(22): 7611-4.

23. Kumbaraci V, Aydogan B, Talinli N, Yagci Y. Naphthodioxinone-1, 3-benzodioxole as photochemically masked one-component type II photoinitiator for free radical polymerization. Journal of Polymer Science Part A: Polymer Chemistry. 2012; 50(13): 2612-8.

24. Tasdelen MA, Kumbaraci V, Jockusch S, Turro NJ, Talinli N, Yagci Y. Photoacid generation by stepwise two-photon absorption: photoinitiated cationic polymerization of cyclohexene oxide by using benzodioxinone in the presence of iodonium salt. Macromolecules, 2008. 41(2): 295-7.

25. Leibfarth FA, Kang M, Ham M, Kim J, Campos LM, Gupto N, Moon B, Hawker CJ. A facile route to ketene-functionalized polymers for general materials applications. Nature Chemistry. 2010; 2(3): 207-12.

26. Leibfarth FA, Schneider $Y$, Lynd NA, Schultz A, Moon B, Kramer EJ, Bazan GC, Hawker CJ. Ketene functionalized polyethylene: Control of cross-link density and material properties. Journal of the American Chemical Society. 2010; 132(42): 147069

27. Wolffs $M$, Kade MJ, Hawker CJ. An energy efficient and facile synthesis of high molecular weight polyesters using ketenes. Chemical Communications. 2011; 47(38): 10572-4.

28. Arslan M, Motallebzadeh A, Kiskan B, Demirel AL, Kumbaraci V, Yagci Y. Combining benzoxazine and ketene chemistries for self-healing of high performance thermoset surfaces. Polymer Chemistry. 2018; 9(15): 2031-9.

29. Alkan Goksu Y, Kumbaraci V, Yagci Y. Modular photoinduced grafting onto approach by ketene chemistry. Journal of Polymer Science Part A: Polymer Chemistry. 2019; 57(3): 274-80.

30. Aydogan C, Ciftci M, Kumbaraci V, Talinli N, Yagci Y. Hyperbranced Polymers by Photoinduced Self-Condensing Vinyl Polymerization Using Bisbenzodioxinone. Macromolecular Chemistry and Physics. 2017; 218(10): 1700045.

31. Cross SE, Anderson C, Roberts MS. Topical penetration of commercial salicylate esters and salts using human isolated skin and clinical microdialysis studies. British Journal of Clinical Pharmacology. 1998; 46(1): 29-35.

32. Durmaz $Y Y$, Kumbaraci $V$, Demirel AL, Talinli N, Yagci Y. Graft Copolymers by the Combination of 
ATRP and Photochemical Acylation Process by Using Benzodioxinones. Macromolecules. 2009; 42(11): 3743-3749.

33. Soltani O, De Brabander JK. Synthesis of functionalized salicylate esters and amides by photochemical acylation. Angewandte Chemie International Edition. 2005; 44(11): 1696-9.

34. Tasdelen MA, Taskin OS, Celik C. Orthogonal Synthesis of Block Copolymer via Photoinduced CuAAC and Ketene Chemistries. Macromolecular Rapid Communications. 2016; 37(6): 521-6.

35. Kumbaraci V, Talinli N, Yagci Y. Photoinduced crosslinking of polymers containing pendant hydroxyl groups by using bisbenzodioxinones. Macromolecular Rapid Communications. 2007; 28(1): 72-7.

36. Patel $M$, Braden $M$, Davy $K$. Polymerization shrinkage of methacrylate esters. Biomaterials. 1987; 8(1): 53-6.

37. Levi G, Karel M. Volumetric shrinkage (collapse) in freeze-dried carbohydrates above their glass transition temperature. Food Research International. 1995; 28(2): 145-51.

38. Dewaele $M$, Asmussen $E$, Peutzfedt $A$, Munksgaard EC, Benetti AR, Finne G, Leloup G, Devaux J. Influence of curing protocol on selected properties of light-curing polymers: degree of conversion, volume contraction, elastic modulus, and glass transition temperature. Dental Materials. 2009; 25(12): 1576-84

39. Caykara T, Özyürek C, Kantoğlu Ö. Investigation of thermal behavior of poly (2-hydroxyethyl methacrylate-co-itaconic acid) networks. Journal of Applied Polymer Science. 2007; 103(3): 1602-7.

40. Acevedo B, Martinez F, Olea A. Synthesis, thermal behavior, and aggregation in aqueous solution of poly (methyl methacrylate)-b-poly (2hydroxyethyl methacrylate). Journal of the Chilean Chemical Society. 2013; 58(4): 2038-42.

41. Marcilla A, Beltran M. Kinetic study of the thermal decomposition of polystyrene and polyethylene-vinyl acetate graft copolymers by thermogravimetric analysis. Polymer Degradation and Stability. 1995; 50(1): 117-24.

42. Maurin MB, Dittert LW, Hussain AA. Thermogravimetric analysis of ethylene-vinyl acetate copolymers with Fourier transform infrared analysis of the pyrolysis products. Thermochimica Acta. 1991; 186(1): 97-102. 
